\title{
The influence of pre-treatment gas mixture upon the ammonia synthesis activity of Co-Re catalysts
}

\author{
K. McAulay ${ }^{\text {a }}$, J.S.J. Hargreaves ${ }^{\text {a, }}$, A.R. McFarlane ${ }^{\text {a }}$, D.J. Price ${ }^{\text {a }}$, N.A. Spencer ${ }^{\text {a }}$, N. Bion ${ }^{\text {b }}$, F. Can ${ }^{\text {b }}$, M. Richard ${ }^{\text {b }}$, \\ H.F. Greer ${ }^{c}$, W.Z. Zhou ${ }^{\mathrm{c}}$ \\ a WestCHEM, School of Chemistry, Joseph Black Building, University of Glasgow, Glasgow G12 8QQ UK \\ b University of Poitiers, CNRS UMR 7285 Institut de Chimie des Milieux et Matériaux de Poitiers (IC2MP), 4 rue Michel Brunet, TSA 51106,86073 Poitiers Cedex 9, France \\ c EaSTCHEM, School of Chemistry, Purdie Building, University of St Andrews, St Andrews, KY16 9ST, UK
}

\section{A R T I C L E I N F O}

\section{Article history:}

Received 21 February 2015

Received in revised form 30 March 2015

Accepted 10 April 2015

Available online 12 April 2015

\section{Keywords:}

Ammonia

Cobalt

Rhenium

Nitride

Hydrogen

\begin{abstract}
A B S T R A C T
CoRe ${ }_{4}$ catalysts highly active for ammonia synthesis at ambient pressure and $400^{\circ} \mathrm{C}$ can be prepared without an ammonolysis stage. Pre-treatments under 3:1 $\mathrm{H}_{2}: \mathrm{N}_{2}$ and 3:1 $\mathrm{H}_{2}$ :Ar atmospheres are shown to influence catalytic performance with the latter treatment leading to an induction period prior to development of activity upon switching to an ammonia synthesis feedstream. The difference in behaviour between the two pre-treatment atmospheres is manifested in temperature programmed nitrogen isotopic exchange experiments where $\mathrm{H}_{2}: \mathrm{Ar}$ treated material is inactive and its $\mathrm{H}_{2}: \mathrm{N}_{2}$ treated counterpart is active.
\end{abstract}

(c) 2015 The Authors. Published by Elsevier B.V. This is an open access article under the CC BY license (http://creativecommons.org/licenses/by/4.0/).

\section{Introduction}

Ammonia synthesis is a reaction of pivotal importance. Through the provision of synthetic fertilisers accomplished via the Haber Bosch Process, it can be directly credited with sustaining a large proportion of the world's population. The Haber Bosch Process involves the direct combination of pure $\mathrm{N}_{2}$ and $\mathrm{H}_{2}$ feedstreams via the use of promoted iron based catalysts [1]. It is operated at high pressure (ca. 100-300 atm) and moderate temperatures (ca. $400{ }^{\circ} \mathrm{C}$ ) and in its entirety, including the production of the pure reactant streams, it is responsible for more than $1 \%$ of global energy demand. Whilst often viewed as a mature technology, the development of more active and/or poison tolerant catalysts could yield massive environmental and economic returns given the energy intensive nature of the process. Indeed, in principle, improvements made in catalyst activity could lead to a "win-win" situation since the moderately exothermic nature of the reaction between $\mathrm{N}_{2}$ and $\mathrm{H}_{2}$ means that the $\mathrm{NH}_{3}$ synthesis equilibrium is favoured by a decrease in temperature.

It has been established that ruthenium based catalysts are effective alternatives to iron and they are of higher activity. To this end, $\mathrm{Ru} / \mathrm{C}$ based catalysts are employed on an industrial scale resulting in a reduction in the severity of process operation. This is the basis of the KBR

\footnotetext{
* Corresponding author.

E-mail address: justinh@chem.gla.ac.uk (J.S.J. Hargreaves).
}

Advanced Ammonia Process which is operated at lower pressure than in the Haber Bosch counterpart [2]. Investigations into Ru catalysed ammonia synthesis are on-going with very recent literature documenting very high activity for electride supported Ru catalysts [3]. Additional literature has reported that certain nitrides exhibit high activity, with $\mathrm{Co}_{3} \mathrm{Mo}_{3} \mathrm{~N}$ based systems being particularly noteworthy [4-6], although high activity has also been documented for other systems such as $\mathrm{Ni}_{2} \mathrm{Mo}_{3} \mathrm{~N}$ [4] which could offer advantages in terms of ease of nitridation [7]. Attention has also centred upon Re based catalysts, with bulk Re modified with Co (in the atomic ratio 4:1 Re:Co, hereafter referred to as $\mathrm{CoRe}_{4}$ ) having been reported to be particularly active [8]. In the case of catalysts comprising of Re alone, a marked degree of deactivation with time on stream was evidenced which has been attributed to decomposition of the active nitride phase to a mixture of rhenium nitride and rhenium metal $[8,9]$. The high activity of $\mathrm{CoRe}_{4}$ has been attributed to stabilisation of a nitride phase [8]. Further support for the formation of an active nitride in Re based systems is presented in a study of a caesium promoted rhenium catalyst supported on alumina where a pronounced influence of pre-treatment gas was reported with $3: 1 \mathrm{H}_{2}: \mathrm{N}_{2}$ leading to more active catalysts than $\mathrm{H}_{2}$ alone [10]. In view of the difficulties encountered in characterising the rhenium nitride phases reported in the preceding study, coupled to the high activities of the systems and the importance of ammonia synthesis, we are undertaking an investigation of the $\mathrm{CoRe}_{4}$ system. In this communication, we report 
our initial results upon the influence of the composition of the pretreatment gas mixture.

\section{Experimental}

$\mathrm{CoRe}_{4}$ samples were prepared by mixing $4 \mathrm{~g}$ of $\mathrm{NH}_{4} \mathrm{ReO}_{4}$ (Sigma Aldrich $\geq 99 \%$ ) in $2 \mathrm{ml}$ of distilled water with ca. $1 \mathrm{~g} \mathrm{Co}\left(\mathrm{NO}_{3}\right)_{2} \cdot 6 \mathrm{H}_{2} \mathrm{O}$ (Sigma Aldrich $\geq 98 \%$ ). The resultant mixture was dried in air at $125^{\circ} \mathrm{C}$ for $12 \mathrm{~h}$. The dry materials were then calcined in air at $700{ }^{\circ} \mathrm{C}$ (applying a $10{ }^{\circ} \mathrm{C} \mathrm{min}{ }^{-1}$ ramp rate) for $3 \mathrm{~h}$. Reaction studies were performed using ca. $0.3 \mathrm{~g}$ of material which was placed in a silica reactor tube held between silica wool plugs. Prior to reaction, samples were either activated in situ in the microreactor for $2 \mathrm{~h}$ at $600{ }^{\circ} \mathrm{C}$ under a $60 \mathrm{ml} \mathrm{min}{ }^{-1}$ flow rate of either 3:1 $\mathrm{H}_{2}: \mathrm{N}_{2}$ (BOC, $\mathrm{H}_{2} 99.998 \%, \mathrm{~N}_{2}$ 99.995\%) or 3:1 $\mathrm{H}_{2}: \mathrm{Ar}$ (BOC, $\mathrm{H}_{2}$ 99.998\%, Ar min. 99.99\%.). Following activation, reactions were undertaken applying the $3: 1 \mathrm{H}_{2}: \mathrm{N}_{2}$ feed gas flowing at $60 \mathrm{ml} \mathrm{min}^{-1}$ at ambient pressure and a temperature of $400{ }^{\circ} \mathrm{C}$. The vent gas was flowed through $200 \mathrm{ml}$ of $0.00108 \mathrm{M} \mathrm{H}_{2} \mathrm{SO}_{4}$ solution and the rate of ammonia production was calculated from the decrease of conductivity monitored as a function of reaction time. Ammonia formation was also verified for selected reactions using a test employing Nessler's reagent.

Powder X-ray diffraction patterns were recorded using a Siemens D5000 diffractometer using $\mathrm{Cu} \mathrm{K}_{\alpha 1}$ radiation. Samples were prepared by compaction into a sample holder and measurements were undertaken over the $5-85^{\circ} 2 \theta$ range using a step size of $0.01^{\circ}$ and a counting rate of $1 \mathrm{~s}$ per step. $\mathrm{N}$ analyses were undertaken using an Exeter Analytical CE-440 elemental analyser. Transmission electron microscopic (TEM) images were attained using a JEOL JEM-2011 electron microscope operating at an accelerating voltage of $200 \mathrm{kV}$. The TEM and high-resolution TEM (HRTEM) images were recorded using a Gatan 794 CCD camera.

$\mathrm{N}_{2}$ isotopic exchange measurements were performed using the apparatus developed for oxygen isotopic exchange studies described previously $[11,12]$. A U-form reactor was placed in a closed recycle system which was connected on one side to a mass spectrometer (Pfeiffer Vacuum, QMS 200) for monitoring the gas phase composition and on the other side by a vacuum pump. The recycling pump placed in the system removes limitations due to gas-phase diffusion. Temperature programmed ${ }^{15} \mathrm{~N}_{2} /{ }^{14} \mathrm{~N}_{2}$ homomolecular exchange $\left({ }^{15} \mathrm{~N}_{2(\mathrm{~g})}+{ }^{14} \mathrm{~N}_{2(\mathrm{~g})} \rightarrow 2{ }^{14} \mathrm{~N}^{15} \mathrm{~N}_{(\mathrm{g})}\right)$ experiments were undertaken on $100 \mathrm{mg}$ of $\mathrm{CoRe}_{4}$ as described below. Samples were subjected to either a $3: 1 \mathrm{H}_{2}: \mathrm{N}_{2}$ or $3: 1 \mathrm{H}_{2}: \mathrm{Ar}\left(80 \mathrm{ml} \mathrm{min}^{-1}\right)$ pre-treatment step at $600{ }^{\circ} \mathrm{C}$ for $1 \mathrm{~h}$ with a ramp rate of $10^{\circ} \mathrm{C} \mathrm{min}{ }^{-1}$ prior to cooling to $200^{\circ} \mathrm{C}$ under the same gas mixture. Then, the system was purged using secondary vacuum at $200{ }^{\circ} \mathrm{C}$ for 1 h. 50 mbar of a mixture of ${ }^{14} \mathrm{~N}_{2}$ and ${ }^{15} \mathrm{~N}_{2}$ (98\% + purity, supplied by Cambridge Isotope Laboratories, Inc.) was charged into the recycle system at $200^{\circ} \mathrm{C}$ and the temperature was increased with a ramp rate of $2{ }^{\circ} \mathrm{C} \mathrm{min}^{-1}$ up to $600{ }^{\circ} \mathrm{C}$. Another experiment of homomolecular exchange was undertaken with the addition of an activation step: After $\mathrm{H}_{2}: \mathrm{N}_{2}$ treatment, the catalyst was purged using $\mathrm{N}_{2}$ flow ( $20 \mathrm{ml} \mathrm{min}{ }^{-1}$ ) at $600{ }^{\circ} \mathrm{C}$ for $30 \mathrm{~min}$ prior to cooling down to $200{ }^{\circ} \mathrm{C}$ under $\mathrm{N}_{2}$. The masses $28,29,30 \mathrm{~m} / \mathrm{z}$ were monitored as a function of time to follow the exchange and converted into ${ }^{14} \mathrm{~N}_{2}$, ${ }^{14} \mathrm{~N}^{15} \mathrm{~N}$ and ${ }^{15} \mathrm{~N}_{2}$ partial pressures respectively. The $\mathrm{m} / \mathrm{z}$ values of 2,17 and 18 were also recorded to determine if $\mathrm{H}$ atoms remained at the surface of the nitride, thus yielding $\mathrm{NH}_{3}$ or $\mathrm{H}_{2}$ in the gas phase after decomposition. The absence of $\mathrm{NO}_{\mathrm{x}}$ and $\mathrm{O}_{2}$ was confirmed by monitoring the corresponding $\mathrm{m} / \mathrm{z}$ values. The quantity of $\mathrm{H}_{2}$ (mbar) was also estimated after the calibration step.

\section{Results and discussion}

Within the literature, active $\mathrm{CoRe}_{4}$ catalysts have been prepared by pre-treatment of their precursors with $\mathrm{NH}_{3}[8,9]$. However, as discussed by Wise and Markel in relation to the binary molybdenum nitride system, ammonolysis is not practical on a large scale for the preparation of nitrides from oxide precursors [13]. A number of issues such as heat transfer mean nitridation from reactant $\mathrm{H}_{2}: \mathrm{N}_{2}$ mixtures would be preferable. Accordingly, in this study, reduction has been undertaken using $\mathrm{H}_{2}: \mathrm{N}_{2}$ (3:1) with $\mathrm{H}_{2}$ : $\operatorname{Ar}$ (3:1) being employed for means of comparison to assess any potential role of possible nitride formation. For both resultant materials, the ambient pressure steady state ammonia synthesis activities at $400{ }^{\circ} \mathrm{C}$ are reported in Table 1 . From the table it can be seen that ammonolysis is not a necessary step in the preparation of active catalysts and indeed the mass normalised rates determined exceed that of the material prepared by ammonolysis and run under comparable conditions as reported elsewhere (where rates of $600 \mu \mathrm{mol} \mathrm{g}{ }^{-1} \mathrm{~h}^{-1}$ [8] and ca. $470 \mu \mathrm{mol} \mathrm{g}{ }^{-1} \mathrm{~h}^{-1}$ [9] have been quoted). If thermodynamic equilibrium was attained under the reaction conditions, employed it would correspond to a mass normalised rate of ca. $2140 \mu \mathrm{mol} \mathrm{g} \mathrm{g}^{-1} \mathrm{~h}^{-1}$. Upon making comparisons with other systems reported to display high activity in the literature, rates of $652 \mu \mathrm{mol} \mathrm{g}-1 \mathrm{~h}^{-1}$ for $\mathrm{Co}_{3} \mathrm{Mo}_{3} \mathrm{~N}$ [5], ca. $400 \mu \mathrm{mol} \mathrm{g}^{-1} \mathrm{~h}^{-1}$ for $\mathrm{Ni}_{2} \mathrm{Mo}_{3} \mathrm{~N}$ [7] and $437 \mu \mathrm{mol} \mathrm{g}^{-1} \mathrm{~h}^{-1}$ for Re/MCM-41 [14] have been reported for conditions comparable to those applied in this study. In the case of Ru dispersed on electride, a rate of $3550 \mu \mathrm{mol} \mathrm{g} \mathrm{cat}^{-1} \mathrm{~h}^{-1}$ has been reported at atmospheric pressure and $340{ }^{\circ} \mathrm{C}[3]$.

Comparing the data in Table 1 , a degree of influence of pretreatment gas can be seen. Interestingly, as apparent in Fig. 1, there is an induction period associated with the development of activity in the case of the $\mathrm{H}_{2}$ :Ar pre-treated material. This is in marked contrast to that treated under $\mathrm{H}_{2}: \mathrm{N}_{2}$ and could tentatively be associated with the formation of an active nitride phase as proposed by Kojima and Aika [8]. In terms of the reaction profile, it is of interest to note that beyond the induction period, during which the material is apparently inactive, the catalyst exhibits steady state performance. In view of the earlier reports wherein $\mathrm{Re}_{3} \mathrm{~N}$ showed a pronounced deactivation rate within the first $2 \mathrm{~h}$ on stream at ambient pressure and $350{ }^{\circ} \mathrm{C}$ [8], we have undertaken extended testing of a $\mathrm{CoRe}_{4}$ catalyst prepared by pre-treatment with $\mathrm{H}_{2}: \mathrm{N}_{2}$ and have shown it to exhibit steady state activity throughout an entire $48 \mathrm{~h}$ testing period. When pre-treated with $\mathrm{H}_{2}: \mathrm{N}_{2}$, the $\mathrm{CoRe}_{4}$ material exhibits a steady state ammonia synthesis rate of $576 \pm 86 \mu \mathrm{mol} \mathrm{g}^{-1} \mathrm{~h}^{-1}$ at $350{ }^{\circ} \mathrm{C}$.

To obtain a more complete understanding of the role of pretreatment and fundamental aspects of nitrogen activation, temperature programmed homomolecular exchange of a ${ }^{14} \mathrm{~N}_{2}:{ }^{15} \mathrm{~N}_{2}$ mixture has been conducted. This process can be indicative of some of the fundamental $\mathrm{N}_{2}$ activation steps. As can be observed in Fig. 2, there are significant differences between the exchange profiles as a function of pre-treatment. In the case of the $\mathrm{H}_{2}$ :Ar pre-treated sample, the ${ }^{14} \mathrm{~N}_{2}{ }^{15} \mathrm{~N}_{2}$ homoexchange reaction does not occur within the temperature range applied. However, in the case of the $\mathrm{H}_{2}: \mathrm{N}_{2}$ pre-treated system, there seems to be release of a very low amount of hydrogen (the maximum pressure recorded at $550{ }^{\circ} \mathrm{C}$ is about $0.1 \mathrm{mbar}$ ) followed by development of $\mathrm{N}_{2}$ homolytic exchange. This clearly indicates the importance of pre-treatment with the $\mathrm{N}_{2}$ containing mixture in the generation of an active surface. In addition, it has been observed that application of the secondary vacuum step at $600{ }^{\circ} \mathrm{C}$ yields materials which do not desorb hydrogen and which are unreactive for $\mathrm{N}_{2}$ exchange whereas replacing this step by a $30 \mathrm{~min}$ $600{ }^{\circ} \mathrm{C} \mathrm{N} \mathrm{N}_{2}$ pre-treatment step does result in exchange which once again may follow evolution of a very small amount of $\mathrm{H}_{2}$. These observations may have interesting implications since it could be imagined that in vacuo at $600{ }^{\circ} \mathrm{CH}_{2}$ loss and/or removal of surface nitride may occur. It

Table 1

Mass normalised steady state ammonia synthesis rates at $400{ }^{\circ} \mathrm{C}$ for $\mathrm{CoRe}_{4}$ samples as a function of pre-treatment gas.

\begin{tabular}{ll}
\hline Pre-treatment atmosphere & Ammonia synthesis rate $\left(\mu \mathrm{mol} \mathrm{NH} \mathrm{g}^{-1} \mathrm{~h}^{-1}\right)$ \\
\hline $\mathrm{N}_{2} / \mathrm{H}_{2}$ & $943 \pm 44$ \\
$\mathrm{Ar} / \mathrm{H}_{2}$ & $844 \pm 41$ \\
\hline
\end{tabular}


a)

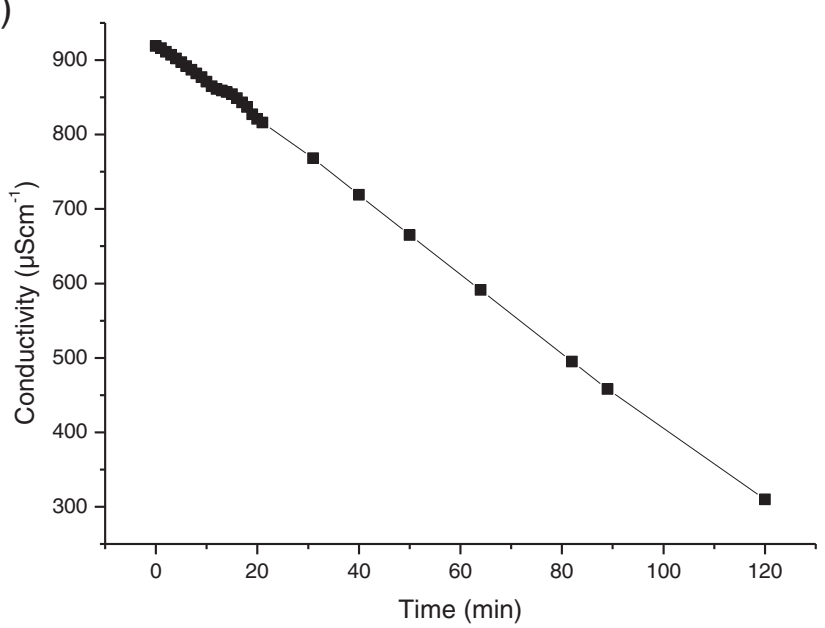

b)

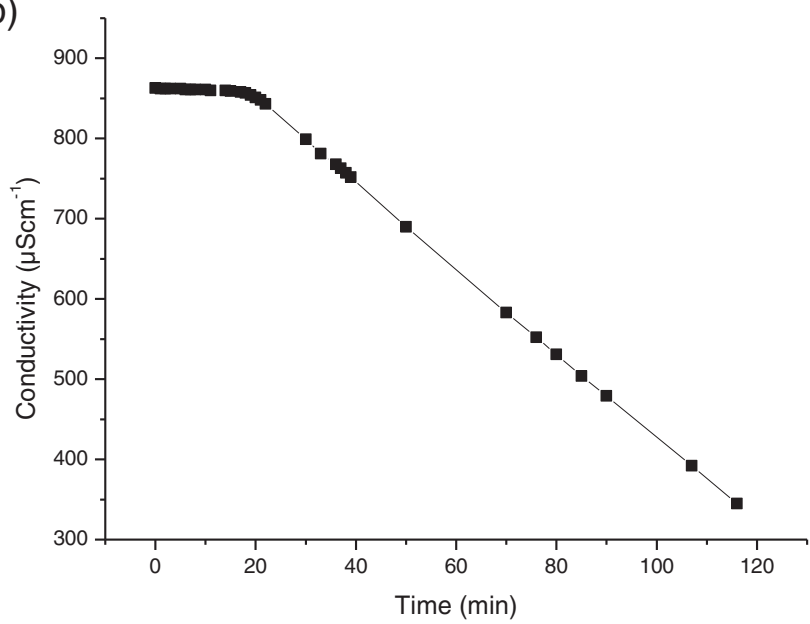

Fig. 1. Reaction conductivity profiles for $3: 1 \mathrm{H}_{2}: \mathrm{N}_{2}$ reaction at $400{ }^{\circ} \mathrm{C}$ (a) sample pretreated with $3: 1 \mathrm{H}_{2}: \mathrm{N}_{2}$ for $2 \mathrm{~h}$ at $600{ }^{\circ} \mathrm{C}$ and (b) sample pre-treated with $3: 1 \mathrm{H}_{2}:$ Ar for $2 \mathrm{~h}$ at $600{ }^{\circ} \mathrm{C}$. The plots are truncated to demonstrate the initial period of activity illustrating the different effects of pre-treatment.

could also be the case that there are subtle changes in surface structure and/or composition which lead to the loss of $\mathrm{N}_{2}$ activation ability and the application of in-situ XPS studies to probe these possibilities will be explored. In addition to activity for nitrogen activation, the evolution of $\mathrm{H}_{2}$ suggests $\mathrm{N}_{2}: \mathrm{H}_{2}$ pre-treatment to lead to strong hydrogen adsorption.

In order to further elucidate the effect of the pre-treatment, a range of characterisation studies has been undertaken. Post-reaction powder X-ray diffraction patterns for materials activated under both $\mathrm{H}_{2}$ : $\mathrm{Ar}$ and $\mathrm{H}_{2}: \mathrm{N}_{2}$, presented in Fig. 3, are consistent with the presence of rhenium, although it should be noted that the high backgrounds could disguise a significant degree of X-ray amorphous material. In addition, no cobalt containing phases are evident despite its relatively high concentration. This is contrary to the situation which pertains for the XRD patterns for $\mathrm{CoRe}_{4}$ catalysts prepared by ammonolysis where a mixture of both Co and Re reflections is apparent $[8,9]$. Most interestingly, the background of the $\mathrm{H}_{2}: \mathrm{N}_{2}$ pre-treated material in the range ca $37.5-50^{\circ} 2 \theta$ shows a possible broad feature distinctly difference with respect to its $\mathrm{H}_{2}$ :Ar pre-treated counterpart. Such a feature may be attributed to rhenium nitride, as reported elsewhere [10]. However, post-reaction nitrogen analyses undertaken by combustion upon both samples returned a nil result suggesting a very low (if any) content of $\mathrm{N}$, which could still be consistent with the
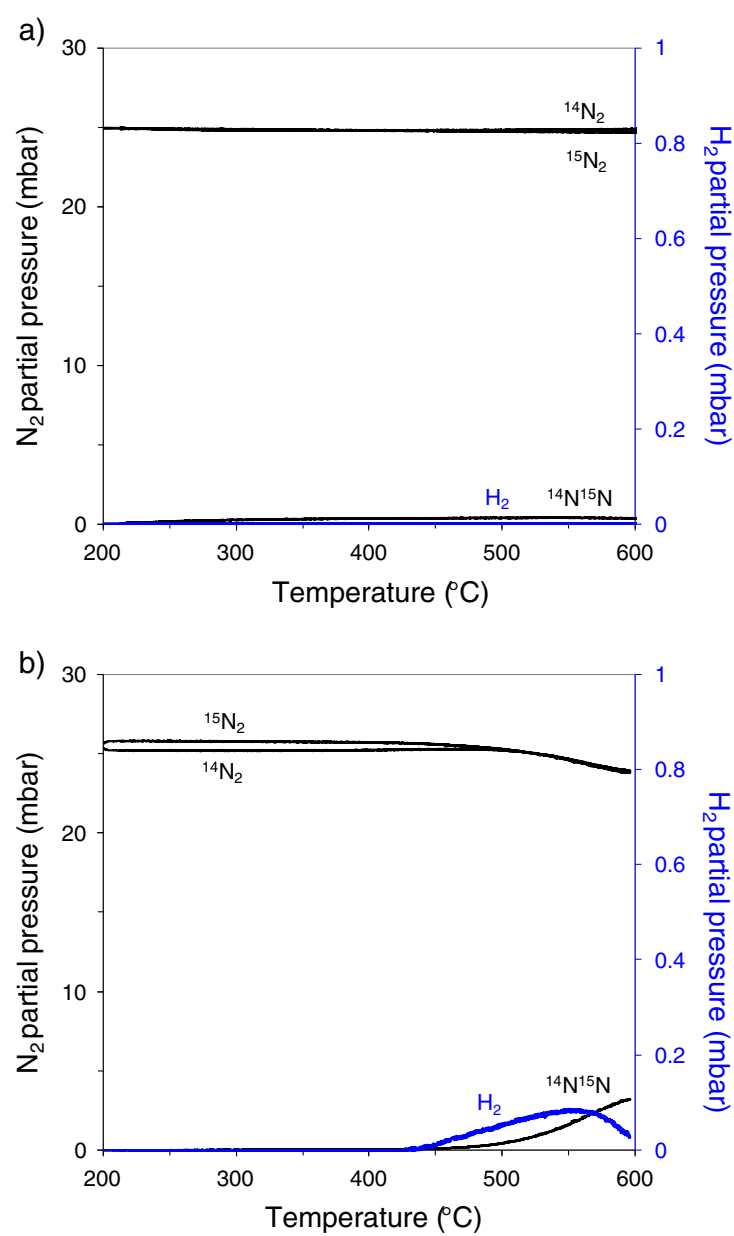

Fig. 2. Temperature programmed ${ }^{14} \mathrm{~N}_{2} /{ }^{15} \mathrm{~N}_{2}$ homomolecular exchange profiles for (a) $\mathrm{CoRe}_{4}$ pre-treated with $3: 1 \mathrm{H}_{2}: \mathrm{Ar}$ at $600{ }^{\circ} \mathrm{C}$ for $1 \mathrm{~h}$ and application of a secondary vacuum at $200{ }^{\circ} \mathrm{C}$ for $1 \mathrm{~h}$ and (b) $\mathrm{CoRe}_{4}$ pre-treated with $3: 1 \mathrm{H}_{2}: \mathrm{N}_{2}$ at $600{ }^{\circ} \mathrm{C}$ for $1 \mathrm{~h}$ and application of a secondary vacuum at $200^{\circ} \mathrm{C}$ for $1 \mathrm{~h}$.

a)

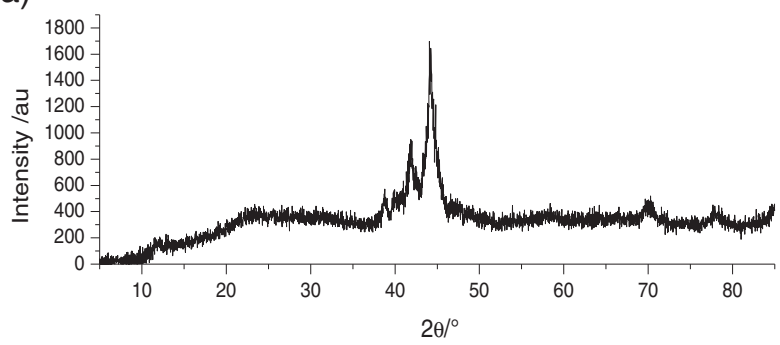

b)

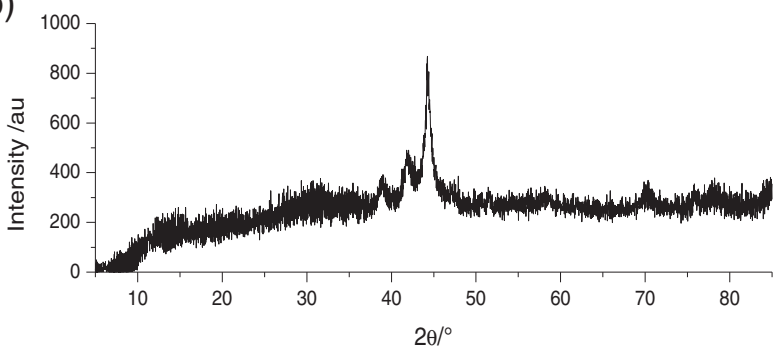

Fig. 3. Powder X-ray diffraction patterns of $\mathrm{CoRe}_{4}$ samples following reaction with $3: 1$ $\mathrm{H}_{2}: \mathrm{N}_{2}$ at $400{ }^{\circ} \mathrm{C}$ and ambient pressure (a) sample pre-treated with $3: 1 \mathrm{H}_{2}: \mathrm{N}_{2}$ at $600{ }^{\circ} \mathrm{C}$ for $2 \mathrm{~h}$ and (b) sample pre-treated with $3: 1 \mathrm{H}_{2}: \mathrm{Ar}$ at $600{ }^{\circ} \mathrm{C}$ for $2 \mathrm{~h}$. 
presence of a surface and/or stable nitride phase in the case of the $\mathrm{H}_{2}: \mathrm{N}_{2}$ activated material.

TEM studies of both materials, both directly after the activation process and also after reaction, have been undertaken to determine potential differences in morphology and to provide a more detailed insight into any phases not apparent in the XRD studies. Representative micrographs are shown in Fig. 4. In these studies, a pronounced amorphous surface film, which is present to a lesser degree in the $\mathrm{H}_{2}$ :Ar pretreated system, was evident in the $\mathrm{H}_{2}: \mathrm{N}_{2}$ pre-treated material. From the image contrast pattern, which is different from that of amorphous carbon and also from the fact that double amorphous layers were sometimes observed, it is believed that this amorphous layer is likely formed due to surface reaction of the particles. Whilst this is a very apparent difference, a degree of caution has to be exercised as to its significance since, although it is clear that the materials behave differently upon pre-treatment, exposure to air has occurred prior to TEM measurement which could result in different degrees of surface oxidation. Overall, the $\mathrm{H}_{2}$ :Ar pre-treated sample appears to be less ordered than its $\mathrm{H}_{2}: \mathrm{N}_{2}$ counterpart. The lattice spacings marked in Fig. 4(c) and (f) are consistent with the (101) plane of Re metal which is evident in the near surface region of samples prepared by both activation procedures, whilst that evident in Fig. 4(i) could correspond to the (111) plane of $\mathrm{Co}_{3} \mathrm{O}_{4}$. $\mathrm{CO}_{3} \mathrm{O}_{4}$ could either indicate incomplete reduction of the sample upon pre-treatment and subsequent reaction or could otherwise be formed by oxidation of reduced Co phase(s) upon the discharge of the catalyst from the reactor and/or its storage in air.

Taken together, a number of the above results provide tentative support for the significance of a nitride phase in relation to the activity of $\mathrm{CoRe}_{4}$ ammonia synthesis catalyst, as detailed elsewhere [8], although such a phase is not directly evident from $\mathrm{N}$ analyses of active materials. However, indirect support for its formation is provided by the induction period evident upon the $\mathrm{H}_{2}$ :Ar pre-treatment and the isotopic $\mathrm{N}_{2}$ exchange behaviour, as well as from the background of the XRD pattern of the $\mathrm{H}_{2}: \mathrm{N}_{2}$ pre-treated catalyst. Alternatively, the different pretreatment procedures may also exert effects by influencing the Co:Re surface ratio. Accordingly, it is our intention to address these aspects in comparative in-situ pre-treated depth profile XPS studies. It is also planned to undertake in-situ XRD/XAS measurements to provide a level of structural detail currently not possible in laboratory XRD investigations. The application of advanced techniques to more directly determine surface structure, also of potential significance, will be investigated. Despite the current uncertainties about the exact nature of the
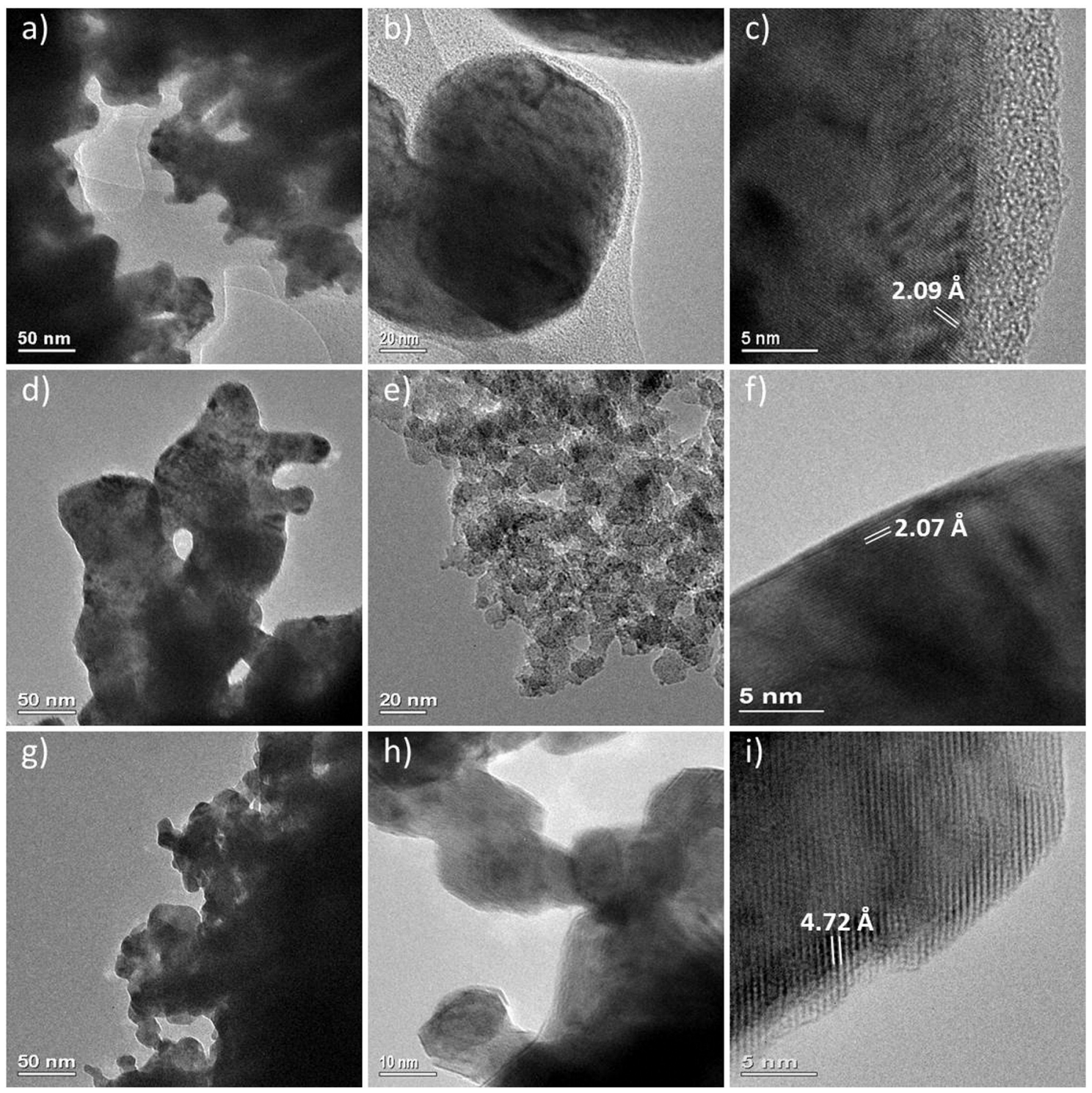

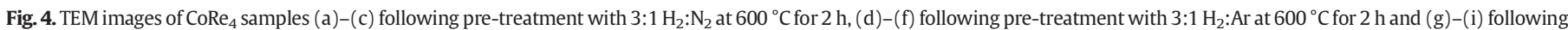
pre-treatment with $3: 1 \mathrm{H}_{2}: \mathrm{N}_{2}$ at $600{ }^{\circ} \mathrm{C}$ for $2 \mathrm{~h}$ and reaction with $3: 1 \mathrm{H}_{2}: \mathrm{N}_{2}$ at $400{ }^{\circ} \mathrm{C}$ and ambient pressure. 
active surface phase, from the results presented herein, it has been shown that ammonolysis is an unnecessary step for the preparation of $\mathrm{CoRe}_{4}$ catalysts and also that such catalysts may be more active than non-promoted ternary nitride systems which have been the subject of some attention in the literature. These interesting findings indicate the system to be of further potential interest.

\section{Conclusions}

This study has demonstrated that it is not necessary to employ ammonolysis of precursors to yield highly active $\mathrm{CoRe}_{4}$ ammonia synthesis catalysts. Employing $\mathrm{H}_{2}: \mathrm{N}_{2}(3: 1)$ and $\mathrm{H}_{2}: \mathrm{Ar}(3: 1)$ pre-treatment leads to significant differences with the latter resulting in an induction period before catalytic activity develops at $400{ }^{\circ} \mathrm{C}$ once the feed is switched to $\mathrm{H}_{2}: \mathrm{N}_{2}$. Detailed combined XRD/XAS studies aimed at elucidating the structural consequences of the two activation procedures will be undertaken as will depth profiling XPS on samples pre-treated in-situ. The differences in activation procedure are mirrored in temperature programmed homomolecular $\mathrm{N}_{2}$ isotopic exchange studies. In these studies $\mathrm{H}_{2}$ :Ar pre-treatment resulted in inactivity for exchange, whereas $\mathrm{H}_{2}: \mathrm{N}_{2}$ resulted in a material exhibiting $\mathrm{N}_{2}$ exchange activity following desorption of hydrogen and providing that the secondary vacuum step was applied below $600{ }^{\circ} \mathrm{C}$.

\section{Acknowledgements}

We would like to thank Mrs Kim Wilson, School of Chemistry, University of Glasgow for very kindly undertaking CHN analyses of materials. KMcA and JSJH would also like to thank the EPSRC and the School of Chemistry, University of Glasgow for the provision of a DTA. Studentship to KMcA (through EP/K503058/1). ARMcF and JSJH gratefully acknowledge the EPSRC for funding through project EP/J018384/1.

\section{References}

[1] R. Schlogl, Catalytic synthesis of ammonia - a "never-ending story"? Angew. Chem. Int. Ed. 42 (2003) 2004-2008.

[2] D.E. Brown, T. Edmonds, R.W. Joyner, J.J. McCarroll, S.R. Tennison, The genesis and development of the commercial BP doubly promoted catalyst for ammonia synthesis, Catal. Lett. 144 (2014) 545-552.

[3] F. Hayashi, M. Kitano, T. Yokoyama, M. Hara, H. Hosono, Surface treatment for conductive $12 \mathrm{CaO} \cdot 7 \mathrm{Al}_{2} \mathrm{O}_{3}$ electride powder by rapid thermal annealing processing and its application to ammonia synthesis, ChemCatChem 6 (2014) 1317-1323.

[4] C.J.H. Jacobsen, Novel class of ammonia synthesis catalysts, Chem. Commun. 1057-1058 (2000).

[5] R. Kojima, K. Aika, Cobalt molybdenum bimetallic nitride catalysts for ammonia synthesis - part 1. Preparation and characterization, Appl. Catal. A: Gen. 215 (2001) 149-160.

[6] D. Mckay, J.S.J. Hargreaves, J.L. Rico, J.L. Rivera, X.-L. Sun, The influence of phase and morphology of molybdenum nitrides on ammonia synthesis activity and reduction characteristics, J. Solid State Chem. 181 (2008) 325-333.

[7] N. Bion, F. Can, J. Cook, J.S.J. Hargreaves, A.L. Hector, W. Levason, A.R. McFarlane, M. Richard, K. Sardar, The role of preparation route upon the ambient pressure ammonia synthesis activity of Ni2Mo3N (Appl. Catal. A: Gen), 2015. http://dx.doi.org/10. 1016/j.apcata.2014.10.030.

[8] R. Kojima, K. Aika, Rhenium containing binary catalysts for ammonia synthesis, Appl. Catal. A Gen. 209 (2001) 317-325.

[9] A.-M. Alexander, J.S.J. Hargreaves, C. Mitchell, The denitridation of nitrides of iron, cobalt and rhenium under hydrogen, Top. Catal. 56 (2013) 1963-1969.

[10] R. Kojima, H. Enomoto, M. Muhler, K. Aika, Cesium-promoted rhenium catalysts supported on alumina for ammonia synthesis, Appl. Catal. A Gen. 246 (2003) 311-322.

[11] D. Martin, D. Duprez, Mobility of surface species on oxides. 1. Isotopic exchange of ${ }^{18} \mathrm{O}_{2}$ with ${ }^{16} \mathrm{O}$ of $\mathrm{SiO}_{2}, \mathrm{Al}_{2} \mathrm{O}_{3}, \mathrm{ZrO}_{2}, \mathrm{MgO}, \mathrm{CeO}_{2}$, and $\mathrm{CeO}_{2}-\mathrm{Al}_{2} \mathrm{O}_{3}$. Activation by noble metals. Correlation with oxide basicity, J. Phys. Chem. 100 (1996) 9429-9438.

[12] D. Duprez, In Isotopes in Heterogeneous Catalysis, in: J.S.J. Hargreaves, S.D. Jackson, G. Webb (Eds.), Imperial College Press, London 2006, p. 133 (Chapter 6).

[13] R.S. Wise, E.J. Markel, Synthesis if high surface area molybdenum nitride in mixtures of nitrogen and hydrogen, J. Catal. 145 (1994) 344-355.

[14] F. Hayashi, M. Iwamoto, Ammonia synthesis over rhenium supported on mesoporous silica MCM-41, Microporous Mesoporous Mater. 146 (2011) 184-189. 